\title{
Viagem ao centro de si mesmo: exílio, autoficção e autoria em A chave de casa e Opisanie Swiata
}

\author{
Erica Rodrigues Fontes*
}

\begin{abstract}
Resumo
O artigo analisa os romances A chave de casa, de Tatiana Salem Levy, e Opisanie Swiata, de Veronica Stigger, duas obras recentes da Literatura Brasileira cujo foco é o deslocamento de protagonistas que previamente já passaram pela experiência de desenraizamento. As narrativas salientam a necessidade de uma nova viagem para os dois personagens. No primeiro romance, o avô da protagonista sugere a ela que vá até a sua casa em Esmirna, Turquia, entregando-lhe a chave da porta da frente da residência. Essa experiência gera um processo de autoconhecimento e uma obra literária sobre a protagonista, que pode ser também a própria autora. $\mathrm{Na}$ segunda obra, Natanael, filho brasileiro do protagonista polonês, solicita a ele, através de carta, uma visita em seu leito de morte, o que faz o pai, Opalka, vir de navio da Europa até a América do Sul. Essas vivências proporcionam ao protagonista uma visitação interior, o que também resulta em uma obra literária. $\mathrm{O}$ objetivo deste trabalho é mostrar como os personagens principais das duas narrativas experimentam uma epifania causada pelo próprio ato de se deslocar e qual é o resultado disso. Sob a luz de Reflexões sobre o exílio e outros ensaios, de Edward Said, e Teoria da viagem, de Michel Onfray, examina-se como, nas obras, ir a Esmirna e à Amazônia brasileira é uma forma tanto de intensificar quanto de amenizar as feridas do exílio anterior que nunca poderão ser, de fato, esquecidas. É, acima de tudo, uma tentativa de reconexão, de profunda ligação consigo mesmo, com a família e a sociedade ao redor, processos que têm na escrita de si sua mais profunda manifestação.
\end{abstract}

Palavras-chave: Literatura Brasileira. Século XXI. Exílio. Identidade. Ficção.

1 Universidade Federal do Piauí (UFPI). Professora Associada. Coordenação de Letras Estrangeiras. 


\section{Introdução}

Não são raros os momentos nos quais deparamo-nos com notícias sobre o êxodo de milhares e milhares de pessoas ao redor do mundo. Durante toda a história da humanidade, tem havido constante fluxo de indivíduos. Não à toa o renomado fotógrafo brasileiro Sebastião Salgado, sediado na França, dedicou toda uma série de fotografias aos temas Êxodos e Migrações, nos quais o fotógrafo apurou o olhar sobre a movimentação humana na Terra. ${ }^{1}$ Essa movimentação de pessoas ocorreu por vários motivos, mas o fato é que sempre se deslocaram, objetivando uma vida mais confortável. Atualmente, não é diferente. Em virtude de conflitos isolados e destruição massiva em alguns territórios, populações inteiras têm se refugiado em países de diversos continentes. Há ainda questões pessoais que favorecem a emigração e posterior imigração de um indivíduo.

A Europa recebe atualmente população de refugiados que supera em número muitas populações de países do continente. A ajuda humanitária necessária a essas pessoas em situação de risco tem gerado problemas constantes, pois abala as estruturas organizacionais dos países acolhedores. O êxodo em massa que ocorre hoje, em virtude da guerra na Síria, do Oriente Médio para a Europa, tem ocupado muito tempo de nossos noticiários e preocupa vários dirigentes políticos. Mas há ainda muitas outras migrações de povos que enfrentam guerras civis ou lidam com desastres naturais frequentes, como é o caso dos haitianos.

O Brasil recebeu e ainda recebe diversos povos que estão em situação de vulnerabilidade em seus países de origem e, em decorrência disso, já presenciou a instalação de várias comunidades estrangeiras em seu território. Ainda no século XX, durante e depois da Segunda Guerra Mundial e uma consequente recessão econômica, o Brasil recebeu alemães, italianos, japoneses, libaneses, poloneses, turcos e pessoas oriundas de várias outras nações. O país se apresentava como terra de oportunidades com excelente clima e economia em crescimento e empregou várias dessas pessoas em atividades de comércio e agricultura, principalmente em estados do Sudeste, Sul e Norte do país. Alguns desses imigrantes nunca mais voltaram à sua terra natal e criaram seus filhos no Brasil como se estivessem em seu país de origem, mas sem deixar de experimentar a nova "casa".

1 As informações foram obtidas no site www.amazon.com.br, http://www.swissinfo.ch/por/ sebasti\%C3\%A3o-salgado-revela-mundo-da--migra\%C3\%A7\%C3\%A3o-/2517076 e Wikipédia. Acesso em: mar. 2017. 
A Literatura Brasileira do século XXI reflete em parte a produção da juventude filha e neta dessa grande leva de imigrantes no Brasil e descortina muitos dos conflitos, desesperos e angústias do fato de ser desenraizado. Muitas vezes, não se está ligado a uma terra física, mas a uma terra imaginada, quase intocável, que se alterou com o tempo, mas não na memória de quem a deixou e a manteve - mentalmente - do jeito que foi deixada. Frequentemente, é essa lembrança engessada que é transmitida de geração em geração. Exatamente por isso, apesar de nascido em determinado local, pode não ser dessa terra a herança familiar do indivíduo, sua cultura, sua forma de ver o mundo, que, muitas vezes, já é passada para os jovens da família através da visão modificada (filtrada) do imigrante. O imigrante, seu filho e neto são seres híbridos. Carregam o peso de vários lugares, várias lembranças, vários sofrimentos. Por isso as histórias por eles narradas são habitadas por personagens que demonstram experiências semelhantes a essas. Mas esses textos também procuram um sentido maior para a vida, uma oportunidade de deixar uma herança cultural para gerações vindouras. Como afirma Sonia Torres: "[...] por que todos eles são, de uma forma ou de outra, histórias sobre o que significa vir de um lugar particular e construir diferentes modalidades de pertencer a determinados locais, nos tempos que vivemos". (TORRES, 2001, p. 15). A literatura advinda dessas vivências é ficção profundamente baseada em fatos reais. Qualquer semelhança não é mera coincidência.

Alguns dos textos mais marcantes da Literatura Brasileira da contemporaneidade falam do exílio como questão central, em uma tentativa de entender a história de diversas gerações a partir do deslocamento e provável nova conexão espacial e cultural. Muitas vezes, esses trabalhos contêm traços de autoficção, apresentando personagens principais que se revelam também escritores, como pode ser observado em A chave de casa e Opisanie Swiata. A experiência do exílio é tão profunda e gera tamanha epifania, que exige documentação - e nada mais envolvente do que escrever e documentar a partir da própria experiência. A protagonista de A chave de casa registra, por escrito, sua experiência na terra do avô, assim como Opalka, que, pouco depois de chegar à Amazônia, decide oficializar suas memórias. 


\section{Tatiana Salem Levy ${ }^{2}$ e A chave de casa}

Tatiana Salem Levy possui obra com tendências claramente autobiográficas. Tanto em A chave de casa quanto em Paraíso, ${ }^{3}$ romance publicado pela Editora Foz, em 2015, as personagens centrais são autoras que escrevem a história que narram.

Levy nasceu em Lisboa, em 1979, durante a Ditadura Militar no Brasil, e posteriormente mudou-se, ainda bebê, para o Rio de Janeiro, com a família. A autora, doutora em Estudos de Literatura pela Pontifícia Universidade Católica do Rio de Janeiro, ${ }^{4}$ escreveu sua tese de doutorado sobre memórias familiares e intitulou-a A chave de casa: experimentos com a herança familiar e literária. De fato, os textos da tese e do romance parcialmente homônimo apresentam semelhanças claras. E as coincidências entre eventos ocorridos na vida da autora e na vida da protagonista não são poucas. Levy nem parece querer manter uma distância em relação à protagonista desse romance. O teor de suas várias publicações no Facebook faz parecer que a protagonista de A chave de casa é a escritora. Não podemos, no entanto, dizer que as duas são exatamente a mesma pessoa, pois isso contraria princípios básicos da ficção literária, como aponta Leyla Perrone-Moisés quando afirma que: "Definir a autoficção literária em sua função de veracidade é uma falácia” (PERRONE-MOISÉS, 2016, p. 209). Mas a trajetória de Levy, neta de turcos judeus imigrados para o Brasil, nos norteia na compreensão da personagem central de A chave de casa, uma mulher que parte em busca do conhecimento de seus antepassados para compreender mais sobre o mundo, sobre os outros e sobre si.

A protagonista — também narradora e escritora — começa sua história afirmando que mal pode se mexer. Tem um fardo de muitos anos sobre as costas. Desde o início, sente um peso que não é só seu. Nasceu com ele. Não anda sozinha, pois, todas as vezes que diz "eu”, é como se estivesse dizendo "nós” (LEVY, 2013, p. 9).

2 As informações sobre a autora foram obtidas em: http://enciclopedia.itaucultural.org.br/pessoa101178/ tatiana-salem-levy. Acesso em: mar. 2017.

3 Mais informações sobre Paraíso podem ser obtidas em: http://www.scielo.br/pdf/elbc/n48/23164018-elbc-48-00209.pdf. Acesso em: mar. 2017.

4 As informações sobre a carreira acadêmica da autora podem ser obtidas através do seu Currículo Lattes publicado em: http://lattes.cnpq.br/2719447900733433 (última atualização em março de 2009). Acesso em: mar. 2017. 
É nessa condição que ela recebe de seu avô a chave de onde ele morara em Esmirna, na Turquia. $\mathrm{O}$ avô simplesmente a entrega e espera que ela dê um destino ao objeto. A protagonista inicia então o percurso que indicará o fio condutor do romance: a ida da protagonista até o país de origem do avô. Em uma movimentação incansável, muitas vezes psicológica, em algo que se assemelha a um filme ou telenovela, há diversos núcleos narrativos, contando várias histórias concomitantes e em vários momentos da vida. Todas as histórias têm relação com a protagonista. Mas nem sempre é dela a voz que se apresenta.

O "nós” é importante porque nenhum dos personagens da história é nomeado. O leitor inicialmente recebe muitas informações sobre as várias situações — ou, como já chamamos aqui, núcleos ou episódios. Só depois é guiado pelas atitudes e personalidade (reveladas tanto nas ações quanto nos mergulhos psicológicos) de cada um para identificar quem está falando, considerando que a narrativa é construída com muitas vozes.

A protagonista decide ir à casa onde o avô residiu em Esmirna, partindo do Brasil para Istambul e de lá para a cidade do avô. Entra em contato com possíveis familiares seus e inicia uma busca pelo edifício em si. Durante o percurso dela, o leitor não tem acesso unicamente a essa viagem, mas a outros pormenores da vida da personagem. Ele se depara, de igual modo, com o envolvimento visceral da personagem com um homem. A descrição detalhada coloca o leitor como espectador - em se considerando a riqueza de imagens evocadas nas experiências eróticas descritas e nos momentos que encaminham o affair para seu fim trágico. Extremamente intensa também é a relação da personagem com a mãe, que morre em um hospital nos Estados Unidos em sua companhia. As duas parecem estar sempre juntas, amalgamadas, até depois da morte. Mas esse "nós" não é somente a voz da protagonista e da mãe. É a voz da protagonista e de todos os indivíduos com quem teve contato e que contribuem para a sua formação. É quase como se cada encontro gerasse nela uma revelação (um momento epifânico), mostrando a ela uma nova possibilidade, uma nova faceta de sua personalidade e individualidade. Sua formação é, portanto, resultado de uma identidade híbrida, instável, que, em contato com o passado ou o presente do outro, descobriu muito sobre si e, em alguns momentos, também se modificou.

A história não se apresenta ao leitor de forma linear. Os episódios não são descritos na ordem em que ocorrem. Às vezes, as situações finais são colocadas para só depois o processo que levou até a situação ser descrito, em outros episódios, 
ainda não necessariamente de forma sucessiva. Há capítulos com pouquíssimas orações, normalmente indicando um momento limítrofe na vida da protagonista. Depois da morte da mãe, quando afirma: "Como é cruel (e bonito) que a vida continue depois de você" (LEVY, 2013, p. 166), ou quando racionaliza suas fantasias sexuais: "Hoje me masturbei pensando em você com outra. Será que estou ficando louca, meu Deus?" (LEVY, 2013, p. 93), ou quando se sente refém do seu companheiro:

"Quando você aproximou docemente os lábios dos meus ouvidos, tive medo, muito medo. Tremi. Tira a roupa. Tira a roupa e me espera na cama, você ordenou. Acuada, obedeci. Nesse dia descobri que não era amor o que sentíamos” (LEVY, 2013, p. 121).

Nesses trechos, as orações breves surgem precisas, externando, através da linguagem, intensas emoções. É um momento de autoanálise, a partir da releitura e verbalização do contato com o outro.

As passagens curtas conferem um novo ritmo à narrativa, alternando trechos longos, breves e muito breves, mostrando ao leitor uma nova forma de degustar a história de uma mulher apaixonada - pelo mundo, pela mãe, pelo avô, pelos homens, pelas mulheres, pela vida. Ao desconhecer a sequência de eventos e não conseguir ordená-los até o final da narrativa, o receptor da obra tem uma experiência peculiar. A priori é cada momento, cada episódio, é o aqui e o agora no momento da leitura que comunica algo. Como um grande quebra-cabeças, a narrativa vai se revelando em partes, até que seja possível ver o todo do que foi narrado. Os trechos só se mostram romance em sua continuidade, assim como o encontro da protagonista consigo mesma - que só é possível através de suas diversas experiências de vida, das quais a viagem para a Turquia surge como a mais reveladora.

\section{Veronica Stigger e Opisanie Swiata}

Em Opisanie Swiata, de Veronica Stigger, similarmente se observa a importância da movimentação (física) do personagem central para um processo de autodescoberta. É na viagem de retorno da Polônia para o Brasil que Opalka tem as maiores revelações de sua vida. Embora nem Opalka e nem os personagens apresentados no romance sejam desenvolvidos psicologicamente como no texto 
de Levy, ao final da narrativa, muito sobre o polonês que caminha em direção ao filho doente é descoberto. Sua experiência epifânica na viagem é tão forte, que sente a necessidade de registrá-la por escrito.

Opisanie Swiata possui ainda outras claras semelhanças com A chave de casa, mas a existência de um protagonista em movimento é precisamente o que nos traz bastante interesse. E o grande acontecimento da narrativa é a viagem à qual o protagonista se submete. Embora haja também vários núcleos nesse romance, as situações narradas se concentram no trem que Opalka utiliza para chegar ao porto e, posteriormente, ao navio que o traz ao Brasil.

Nascida em Porto Alegre no início da década de 70, bacharel em jornalismo e doutora em Teoria e Crítica da Arte pela USP, a escritora Veronica Stigger ${ }^{5}$ parece apresentar uma predileção por personagens planos, sem grande densidade psicológica. Essa característica do trabalho da autora é acentuada pelo fato de que sua obra possui uma predominância de narrativas curtas, como é o caso dos livros de contos $\mathbf{O}$ trágico e outras comédias (7 Letras, 2004), Gran Cabaret Demenzial (publicado pela Cosac Naify, em 2007) e Os anões (Cosac Naify, 2010), que favorecem essa brevidade e superficialidade descritiva e antecedem a obra em questão. Delírio de Damasco (Cultura e Barbárie, 2012) também possui textos breves que, no entanto, não são contos, mas fragmentos de conversas ouvidas nas ruas. A sua obra mais recente, intitulada Sul, de 2016, é composta por diferentes gêneros e contém, na sequência apresentada, um conto, uma peça e um poema. Seus personagens são rasos, mas nem por isso menos interessantes. No caso de Opisanie Swiata, as descobertas com relação à natureza do personagem principal só ocorrem no final, quase como numa "segunda apresentação", pois, durante a história, há uma série de acontecimentos mirabolantes, rápidos, pornográficos e inusitados envolvendo os outros personagens. A narrativa principal possui um narrador que descreve pouco sobre Opalka psicologicamente, mas o polonês é o único que se transforma e se revela ao leitor com mais densidade. Essa transformação o faz esférico, mesmo que isso só aconteça na chegada dele ao Brasil, já na conclusão do romance.

5 As informações sobre a carreira e obras da autora (com exceção da obra em questão neste trabalho) foram obtidas em: http://www.livronautas.com.br/ver-autor/163/veronica-stigger, http:// www.saraivaconteudo.com.br/Entrevistas/Post/10354, https://culturaebarbarie.wordpress.com/tag/ delirio-de-damasco/ e http://www1.folha.uol.com.br/ilustrada/2016/12/1842072-imagens-sangrentasconduzem-bom-novo-livro-de-veronica-stigger.shtml. Acesso em: mar. 2017. 
A presença constante e forte de personagens planos não diminui em nada a obra literária. James Wood sai em defesa desse tipo de personagem, afirmando que muitos são mais interessantes do que os tidos como esféricos.

Se tentar distinguir personagens principais de secundários personagens redondos e planos - e disser que se diferenciam na sutileza, na profundidade, no espaço que ocupam na página, terei de admitir que muitos personagens ditos planos parecem mais vivos e mais interessantes como estudo humano, por mais efêmeros que sejam, do que personagens redondos a que supostamente estão subordinados. (WOOD, 2012, p. 94).

Em muitos momentos, são os personagens secundários que apontam ao leitor, por contraste, um Opalka introspectivo. São esses exatos instantes que, de igual modo, acirram a curiosidade sobre o que está por vir para ele na floresta, onde seu filho se encontra à beira da morte.

Opisanie Swiata significa “A descrição do mundo" e é inspirado no registro de viagens de Marco Polo - Il Milione. Quando traduzido para o polonês, a obra do italiano possui título homônimo ao da obra de Stigger. ${ }^{6} \mathrm{Na}$ edição da Cosac Naify, Stigger conta a história também visualmente, através de diversos elementos. A capa e contracapa possuem, além de informações usuais como nome da obra e do autor, a reprodução do desenho da carta geográfica do Brasil confeccionada para comemorar o primeiro centenário da Independência, do acervo da Fundação Biblioteca Nacional. Ainda um pouco antes do texto impresso, há fotos antigas da Polônia e de navios da Hamburg Südamerikanische — em uma espécie de prévia dos eventos vindouros. O romance é de fato iniciado com um aviso que Opalka recebe do Dr. Amado Silva, médico de Natanael, filho desconhecido do protagonista. O aviso é seguido de uma carta de Natanael para Opalka, pedindo que o pai o visite o quanto antes e oferecendo-se para pagar a viagem dele de navio até o Brasil, onde está em estado débil. Natanael é detalhista em suas observações e sugestões de como o pai deve proceder até chegar ao seu encontro. E, após um momento quase cinematográfico, no qual o título da obra reaparece seguido do nome da autora e patrocinadores, o leitor se depara com a descrição de Bopp, tipo brasileiro caricatural que acompanhará Opalka até o Brasil, desde o primeiro

6 A informação foi obtida em: http://www.livrariacultura.com.br/p/livros/literatura-nacional/romances/ opisanie-swiata-42139486. Acesso em mar. de 2017. 
trecho da viagem do polonês — no trem — até seguirem mar afora com destino à América do Sul.

A surpresa inicial do leitor não é detida na continuação da leitura: a obra segue utilizando diversos gêneros textuais para contar a saga de um homem que sai da Europa até alcançar o Brasil, onde já havia morado. Stigger se utiliza de cartões postais, cardápios, notícias de jornal, anúncios, avisos, fotos e do texto literário em si, para transportar o leitor para a época e o contexto do que está sendo relatado.

Opalka não é desconhecedor do Brasil. Mas o Brasil que conhece é outro, como o alerta Bopp, pouco depois da interação inicial dos dois: "Acho que o senhor não reconheceria o país. Está muito mudado". (STIGGER, 2013, p. 38). Opalka deixou a mulher e o filho para, por sugestão da mulher, que ele não sabia que estava grávida, tentar se recuperar de uma doença em algum estabelecimento de saúde mais estruturado na Europa. Muitos anos depois, a chegada da notícia do péssimo estado de saúde do filho - situação semelhante à qual ele se encontrava quando deixou o Brasil - o abala profundamente e provoca muita introspecção e questionamento. É como se sua vida estivesse sendo reescrita a partir do momento em que ele descobre que sua conexão com uma terra tão distante é bem mais profunda e longa do que imaginara.

Tudo o que ocorre a partir da notícia é, para Opalka, inesperado. Ele parece anestesiado, mas decidido a estar com o filho. O surgimento de Bopp no trem que o leva ao porto e sua interação com ele, primeiro em polonês e depois em português, são momento de frescor, embora inicialmente incômodos, já que Bopp fala alto e não se contém na cabine do trem quando reprova algumas atitudes de um passageiro russo da mesma cabine onde estão ele e Opalka. Bopp tenta ajudar uma passageira italiana que perde sua aranha de estimação - e que se chama Maria Antonieta - e em virtude da perda inicia uma dança louca. Mas, apesar de todos esses momentos incontidos do brasileiro, é Bopp que traz apoio emocional à trajetória de Opalka.

Bopp é o primeiro personagem descrito, mas não difere muito dos outros, que também possuem traços grotescos. Ele descreve superficialmente, em um de seus caderninhos pretos, as especificidades de seus companheiros de viagem, que ele chama de "meus amigos no navio" (STIGGER, 2013, p. 72). Assim, o leitor aprende um pouco mais sobre a andaluza Dona Oliva, viúva e dona de propriedades no Brasil, que quer mostrar a Floresta Amazônica para as sobrinhas; sobre as Olivinhas, sobrinhas de Dona Oliva, jovens e belas, apreciadoras de sopa 
de ervilha; sobre o senhor e a senhora Andrade, que ficaram ricos graças ao café, mas perderam tudo; sobre Hans, alemão, e Curto Chivito, uruguaio, um possível casal descrito como "amigos íntimos". Sobre Opalka, Bopp apenas registra que é "Polonês. Quieto. Discreto" (STIGGER, 2013, p. 73). Quando o navio chega ao Brasil, Opalka e Bopp se deparam com as Clodiás - quatro mulheres que têm o mesmo marido, que assim preferiu nomeá-las para não se confundir. Os diversos personagens — por assim dizer — esdrúxulos, fornecem bastante material para as situações tragicômicas que ocorrem.

A vinda de Opalka para o Brasil é o fio condutor do romance, mas há vários episódios anedóticos curtos durante a viagem ao Brasil. Muitos beiram o absurdo, como a sereia que as mulheres não querem que os maridos vejam por medo de serem seduzidos, mas que se revela um cadáver de mulher boiando no mar com a boca em formato arredondado, como se tivesse cantado um pouco antes de ser atacada por um animal marítimo (STIGGER, 2013, p. 78). Há a orgia prestes a acontecer na cozinha do navio, delatada pelas Olivinhas, que, quando chegam à cozinha, se deparam com o cozinheiro e uma passageira inglesa, e a Senhora Andrade e o imediato quase fazendo sexo (STIGGER, 2013, p. 89). Há o batismo exigido pelo comandante da embarcação para os que são neófitos em viagens marítimas. O batismo mais parece uma Olímpiada, incluindo várias provas para evitar que os passageiros não se machuquem ou se traumatizem ao passarem do Hemisfério Norte para o Hemisfério Sul, pois a falta de cuidado dos passageiros pode fazer com que a "linha" do Equador se "enrole" na quilha ou no leme (STIGGER, 2013, p. 98). O batismo é realizado um pouco antes de a passagem ser efetuada. Mas o real batismo ou passagem ocorre mesmo na vida de Opalka, que, ao chegar ao Brasil e ter notícias do filho morto, é avisado por Jean Pierre, amigo francês do filho e marido das Clodiás, quando este o recebe no porto, que a Polônia foi ocupada em virtude da Segunda Guerra e não seria mais possível para ele voltar ao país natal tão cedo. A impossibilidade de retornar para casa e o início da descoberta de novos detalhes referentes a seu passado mudam-no para sempre.

\section{0 exílio, a escrita e a viagem em Opisanie Swiata e A chave de casa}

Edward Said (2003), em seu Reflexões sobre o exílio e outros ensaios, aponta diferenças entre exilados, refugiados, expatriados e emigrados, mas reconhece que, apesar de inicialmente a condição de exilado significar expulsão, o exilado é de fato 
todo indivíduo impedido de retornar para a terra que considera sua casa (SAID, 2003, p. 54). Apesar de observarmos a situação de Opalka e da protagonista de A chave de casa a partir de uma perspectiva geral no que tange ao deslocamento, os dois personagens são, de acordo com definição de Said, exilados. São, de alguma forma, impedidos de retornar ao lar, mesmo que, em certos momentos, por vontade própria. Ainda nas palavras de Said: "No fim das contas, o exílio não é uma questão de escolha: nascemos nele, ou ele nos acontece". (SAID, 2003, p. 57).

Opisanie Swiata não esclarece as condições nas quais Opalka esteve no Brasil no século XX. Mas mesmo que ele não tenha estado aqui como exilado, a partir do aviso de Jean Pierre sobre a ocupação da Polônia e a Segunda Guerra, Opalka está detido, impedido de retornar, mesmo quando toma conhecimento de que seu filho morrera pouco antes de sua chegada. Em todo o trajeto do polonês até o Brasil, ele está fora de seu ambiente, assim como estão todos os outros passageiros, mas vai chegar a uma terra onde já esteve. No entanto, os muitos anos nos quais deixou de estar no Brasil trazem-no para um lugar quase que totalmente forasteiro, embora tenha um filho no país. Buscando novas raízes, ele procura encontrar seu único filho em país estrangeiro. Quando recebe a informação de que não poderá mais retornar para a Polônia, também descobre que seu filho acabara de morrer. Novamente Opalka se depara com uma sensação de não pertencimento.

A protagonista de A chave de casa nasce em Portugal, no exílio de seus pais comunistas, durante a Ditadura Militar no Brasil. Mesmo após adulta, não consegue se entender e permanecer em um só lugar. Parece que o peso que sente precisa ser retirado, e isso só deverá ocorrer com o conhecimento de tudo o que carrega nas costas, da sua história na Terra. Quando vai à Turquia, em um hamman de Istambul, ela revela à mulher que a massageou e sentiu sua tensão: "Você sabe, essa dor que sinto no corpo, os ombros pesados, é o passado não esquecido que carrego comigo. O passado de gerações e gerações.” (LEVY, 2013, p. 123). A necessidade da ida àquele país não lhe é outorgada pelo avô: ela mesma sente vontade de saber mais do passado da família e, quem sabe, do seu. Quando, no aeroporto, o oficial da imigração diz que ela precisa de visto para entrar no país dos avós, sente-se estranha por não conseguir se comunicar em turco e por precisar de autorização para entrar na terra onde nasceram seus antepassados. Chega à Turquia como turista, mas não quer se sentir ou se comportar como tal. Quando pensa em encontrar Raphael, um provável primo de seu avô, afirma: “É essa 
cidade que procuro, não a cidade dos tapetes e ouros, não a cidade do tabaco e da boa comida, mas a cidade da minha família.” (LEVY, 2013, p. 143). Durante a estada na Europa, percebe que, no Brasil, só era judia uma vez por ano, durante as comemorações familiares anuais (LEVY, 2013, p. 122).

Para Said, os exilados sempre são diferentes, se sentem órfãos (SAID, 2003, p. 55). E se ocupam em muitos momentos com a compensação da perda das raízes (SAID, 2003, p. 54). São seres nômades, divagadores, em busca de algo que não sabem como encontrar. Stuart Hall aponta que o deslocamento geográfico, cultural e individual das pessoas hoje traz para elas uma "crise de identidade" (HALL, 2014, p. 10). Para a personagem central de A chave de casa e para Opalka, o deslocamento é, em si, uma tentativa de religação. E porque o exilado tenta possuir uma identidade, ainda que através de "refrações e descontinuidades" (SAID, 2003, p. 52), não é coincidência que vemos nos dois romances relatos descontínuos, que parecem oriundos de uma identidade fragmentada, de protagonistas exilados que se revelam, de igual modo, escritores de suas vivências. A criação literária aparece, nas duas obras, como processo terapêutico, causadora de dores e curas e possibilitada pela percepção original de quem não pertence a lugar nenhum e vê tudo com olhos curiosos, descobridores. É Onfray que afirma: "O viajante necessita menos uma capacidade teórica do que uma aptidão para a visão." (ONFRAY, 2009, p. 61). A sedução da viagem e a atração pelo exótico e diferente contribuem para a abertura dessa percepção ou, por assim dizer, dessa epifania, ainda que às vezes ela se apresente de forma etnocêntrica.

Se A chave de casa se pretende relato fiel às experiências de Levy, nunca deixa de ser literatura. Após mencionar a recusa de Barthes em não analisar o real, pois não é palpável, a crítica Perrone-Moisés afirma: "Toda e qualquer narrativa, mesmo aquelas que se pretendem mais coladas ao real, têm algo de ficcional." (PERRONE-MOISÉS, 2016, p. 208). O romance da autora portuguesa contraria algumas normas de autoficção conforme apontadas por Philippe Gasparini e comentadas por Perrone-Moisés (2016, p. 207), como, por exemplo, a falta de nomeação da protagonista —, para Gasparini, a autoficção tende a se utilizar de protagonistas que possuem o nome do autor. Notamos também a presença de fatos claramente fictícios, como a paralisia da protagonista, e o assassinato de seu companheiro - e por ela mesma. Não é necessário recorrer à vida pública de Levy para saber o que é e o que não é ficção em sua obra. Na verdade, tudo pode ser ficção ou, para não fugir do pensamento de Barthes, uma realidade alterada 
pela arte. Entendemos, portanto, os romances como fictícios, embora baseados em experiências de exílio de Levy e também de Stigger, que já residiu fora do Brasil algumas vezes. Se olharmos para os dois protagonistas, notamos o poder da escrita sobre eles. Ainda assim, suas observações focalizam contextos nos quais estão inseridos, a partir de uma visão individual. Se Opalka intitula sua obra A descrição do mundo: memórias, não podemos esquecer que são suas "memórias" que não possuem nenhum compromisso com o real, mas com a imaginação do leitor. Na verdade, quando Opalka identifica como chamará seus escritos, nós já tivemos contato com seus registros, ao ler o romance em si, embora isso só nos seja revelado no final. Em A chave de casa, quando a personagem central não encontra a casa pela qual procura, joga, enraivecida, todos os seus registros no chão - até as folhas ainda em branco. Diz que não quer escrever mais, porque a viagem não tem mais razão de existir (LEVY, 2013, p. 149). Mas, ao escrever sobre o momento de se recusar a escrever, ela registra - e modifica - tudo. Para James Wood, "a arte não é a vida, a arte é sempre um artifício, é sempre mimese" (WOOD, 2012, p. 194). Esses momentos de metaficção - quando a ficção fala de si mesma - são facilitados por personagens exilados, não pertencentes a lugar algum, pois: "O novo mundo do exilado é logicamente artificial e sua realidade se parece com a ficção." (SAID, 2003, p. 54).

Neste artigo, procuramos apresentar um estudo dos romances A chave de casa e Opisanie Swiata a partir da condição de exilado de seus protagonistas. Essa condição de desenraizamento e impedimento de retorno à casa deixa marcas profundas e a necessidade pulsante de pertencimento. Se o momento de exílio dos dois é diverso, a protagonista de A chave de casa enfrenta o exílio ainda bebê, e Opalka é impossibilitado de voltar para casa após a deflagração da guerra, as agruras dos dois são análogas, pois de igual modo possuem identidades partidas. A vontade dos dois de viajar não é acidental; muito pelo contrário, é fundamental para um entendimento mais profundo de quem são. Se, através de uma viagem, suas identidades tornam-se fragmentadas, é também através de uma viagem que tentam conhecer mais sobre si e recebem revelações sobre si mesmos. Onfray pergunta sobre si mesmo e o outro na condição de viajante:

O que posso aprender e descobrir a meu respeito se mudo de lugares habituais e modifico minhas referências? O que resta da minha identidade quando são suprimidos vínculos sociais, comunitários, tribais, quando me vejo sozinho, ou quase, num ambiente hostil ou pelo menos inquietante, perturbador, angustiante? (ONFRAY, 2009, p. 75-76). 
É através da viagem à Turquia que a personagem central de A chave de casa assimila sua ligação com esse país. Entende também até que ponto ela é realmente uma judia turca e quer localizar suas raízes para depois talvez até esquecê-las. Semelhantemente, é na viagem ao Brasil que Opalka compreende que, mesmo tendo encontrado o filho morto, ao retornar, também vivencia o passado. A foto que o filho tem do pai na mão, no momento em que morre, é prova viva disso. Onfray diz que "Os filósofos da Antiguidade Grega sabiam a função formadora do deslocamento." (ONFRAY, 2009, p. 81). Mas não eram só eles que sabiam. Os protagonistas dos dois romances aqui estudados percebem muito mais sobre si durante as experiências de deslocamento. E é essa percepção que os faz querer reordenar, rearrumar suas histórias através da escrita. Como aponta Ítalo Calvino: "Cada vida é uma enciclopédia, uma biblioteca, um inventário de objetos, uma amostragem de estilos, onde tudo pode ser continuamente remexido e reordenado de todas as maneiras possíveis." (CALVINO, 2003, p. 140). A escrita surge nessas narrativas como um acerto de contas com o passado, uma profecia, uma promessa de um futuro menos traumático e, para o indivíduo exilado, a remota possibilidade de pertencer.

\title{
Journey to the Center of One's Own Self: Exile, Autofiction and Authorship in A Chave de Casa and Opisanie Swiata
}

\begin{abstract}
The article analyzes the novels A chave de casa, by Tatiana Salem Levy, and Opisanie Swiata, by Veronica Stigger, two recent works from Brazilian Literature whose focus is on the displacement of protagonists who have previously been through the experience of uprooting. The two narratives highlight the need of a new travel experience for both. In the first novel, the protagonist's grandfather suggests that she goes to his house in Izmir, Turkey, giving her the key to its front door. This experience generates a process of self-knowledge and a literary work about the protagonist who may as well be the author. In the second work, Natanael, the Brazilian son of the Polish protagonist, writes a letter asking Opalka to visit him - the son - at his death bed, which makes Opalka come all the way from Europe to South America by ship. These experiences themselves make it possible for the protagonist to visit his own self, which also results in a literary work. The aim of this article is to show how the main characters of both narratives experience epiphany caused by the very act of displacement and what the result of that is. In the light of Edward Said's Reflexões sobre o exílio e outros ensaios and Michel Onfray's Teoria da viagem, we examine how, in the novels, going to Izmir and the Brazilian Amazon is a way to both intensify and soften the injuries from the previous exile which will never be forgotten. It is, above all, an attempt to reconnect, to deeply link with one's
\end{abstract}


own self, with one's own family and the surrounding society, processes

which have in autofiction and authorship their strongest manifestation.

Keywords: Brazilian literature. XXI century. Exile. Identity. Fiction.

\section{Referências}

CALVINO, Ítalo. Seis propostas para o próximo milênio: lições americanas. Tradução de Ivo Barroso. São Paulo: Companhia das Letras, 2003.

HALL, Stuart. A identidade cultural na pós-modernidade. Tradução de Tomaz Tadeu da Silva e Guacira Lopes Louro. Rio de Janeiro: Lamparina, 2014.

LEVY, Tatiana Salem. A chave de casa. Rio de Janeiro: BestBolso, 2013.

ONFRAY, Michel. Teoria da viagem: poética da geografia. Tradução de Paulo Neves. Porto Alegre: L\&PM, 2009.

PERRONE-MOISÉS, Leyla. Mutações da literatura do século XXI. São Paulo: Companhia das Letras, 2016.

SAID, Edward. Reflexões sobre o exílio e outros ensaios. Tradução de Pedro Maia Soares. São Paulo: Companhia das Letras, 2003.

STIGGER, Veronica. Opisanie Swiata. Veronica Stigger. São Paulo: Cosac Naify, 2013.

TORRES, Sonia. Nosotros in USA: literatura, etnografia e geografias de resistência. Rio de Janeiro: Jorge Zahar Editor, 2001.

WOOD, James. Como funciona a ficção. Tradução de Denise Bottmann. São Paulo: Cosac Naify, 2012. 